\title{
The preservation of English Oak in marine environments.
}

\author{
Wren Montgomery ${ }^{\mathrm{a}, \mathrm{c}^{\star}}$, Eleanor J. Schofield ${ }^{\mathrm{b} *}$, Jonathan S. Watson ${ }^{\mathrm{c}}$, Mark A. Sephton ${ }^{\mathrm{c}}$ \\ ${ }^{a}$ Core Research Laboratory, The Natural History Museum, Cromwell Road, South Kensington, \\ London SW7 5BD, UK. \\ bMary Rose Trust, College Road, HM Naval Base, Portsmouth, PO1 3LX, UK \\ 'Organic Geochemistry Laboratory, Department of Earth Science and Engineering, Imperial \\ College London, SW7 2AZ, UK \\ *Wren Montgomery, Eleanor J. Schofield \\ Email: wren.montgomery@nhm.ac.uk, e.schofield@maryrose.org.
}




\begin{abstract}
English oak (Quercus robur) has been used to construct maritime vessels for millennia. These vessels are now large, historically significant artifacts which require assessment and conservation, whether they are still working vessels, conserved in the water, or conserved in dry dock. In the case of shipwrecks yet to be discovered, rapid assessment may be required. To effectively perform conservation, the chemistry of the degraded wood must be fully understood. We used thermally assisted hydrolysis and methylation combined with gas chromatography-mass spectrometry on samples from several younger wooden vessels which were built from the same species of wood and which worked in similarly salty waters to establish baseline acid/aldehyde and syringyl/guiacyl ratios. Samples from the Mary Rose were then interpreted with respect to these ratios. Differences in these ratios indicate the changes in wood chemistry due to long-term exposure to surface sea water, deep seawater, burial while sunken, and chemistry within the artifact itself. These ratios also indicate the effectiveness of polyethylene glycol (PEG), a common consolidant used in wood conservation, in preserving wood chemistry.
\end{abstract}

\title{
Significance Statement
}

Until the 20th century, wood was used to construct the majority of sea-going vessels.

Understanding the chemical effects of long-term exposure of wood to seawater and burial on the seafloor can enhance both historical interpretation and conservation of important vessels and wrecks. The chemical degradation and oxidation of three historic vessels built of English Oak, plus a modern oak sample, were measured and used to interpret the chemical state of multiple samples from the Mary Rose, demonstrating the potential use of this method for assessing other ships and wrecks.

\section{Main Text}

\section{Introduction}

The long maritime history of Britain (1) offers an opportunity for the study of chemical changes in wood after extended immersion in aqueous environments. There are an estimated 46,000 shipwrecks in British waters today (2, 3); an unknown proportion of these are wooden. Rapidly changing coastlines mean that new shipwreck sites can appear and disappear quickly. The ability to rapidly assess the state of a wooden shipwreck will assist in determining what conservation efforts are appropriate. Furthermore, there are a number of preserved wooden vessels in both public and private hands: these massive historic artifacts require continuous care and monitoring (4). The importance of understanding the degradation of wet and waterlogged wood is not just limited to naval architecture; studies have also been carried out on submerged archaeological samples and sites (5), wooden samples from salt mines (6) and active foundations below the water table in Venice, Italy (7).

Over the course of British history, many ships were built of English Oak (Quercus robur), because it was widely available across the country for much of the historic period when ships were built of wood (8). We have obtained samples from a sequence of vessels built from English Oak spanning four centuries, ranging from the Tudor Mary Rose, commissioned in 1509 and launched in 1511, to the Thames sailing barge (SB) Tollesbury, built in 1901 (Table 1). Samples were collected from areas of the ship which were continuously exposed to water (typically seawater) and studied using thermally assisted hydrolysis and methylation combined with gas chromatography-mass spectrometry (THM-GC-MS).

After felling, the chemical and physical degradation of wood depends primarily on environmental conditions, including the availability of oxygen and the presence of wood-degrading organisms. 
Extreme chemical or biological degradation leads to physical degradation, i.e., loss of the artifact. Wood can be degraded by fungi or bacteria. Fungal degradation can be divided into brown rot fungi (BRF), white rot fungi (WRF), and soft rot fungi (SRF). WRF, which mainly affects hardwoods such as oak, can degrade all the components of wood (lignin, and the polysaccharides hemicellulose and cellulose) but may be selective in which components it removes. BRF mostly affect softwoods and mostly degrade the polysaccharides with only minor alteration of the lignin. BRF act through dealkylation, demethylation and demethoxylation, but do not degrade the aromatic rings. SRF are generally common in waterlogged and aquatic environments and, similarly to BRF, mostly degrade the polysaccharides, with only minor alteration of the lignin.

The effects of bacterial degradation will be similar to the effects of BRF, with only minor alteration of the lignin. Unlike fungal degradation, bacterial degradation can also occur under anoxic conditions, such as the interior of wooden artifacts (9). SRF and bacteria are likely drivers of the degradation of submerged timbers; however, once the timbers are exposed to air and no longer waterlogged, the more destructive WRF could become active.

The degradation of hemicellulose and cellulose occurs rapidly within the context of centuries of history (10). To understand the preservation of English oak in marine archaeological samples over these timescales, we focused on the response of compounds associated with lignin degradation.

THM-GC-MS is one standard technique for the analysis of wood (11-13). During thermally assisted hydrolysis and methylation, lignin is fragmented into syringyl and guaiacyl products. The ratio of acids to aldehydes (Ac/Als, $A c / A l_{G}$ ) and the ratio of overall syringyl to guaiacyl (S/G) are used as proxies for the chemical degradation of the lignin. An increase in the Ac/Al ratio indicates oxidative cleavage on the alkyl side chain which has been associated with WRF and some SRF $(14,15)$. The oxidation and cleavage of the $\beta-\mathrm{O}-4$ bond, the most common linkage in lignin, is the primary cause of increases in Ac/Al. In waterlogged wood, an increase in the Ac/Al ratio has rarely been seen, indicating that depolymerization of the lignin is not a major process in this environment (16-20). One proposed major limiting factor is the availability of oxygen $(10,21,22)$.

However, a number of reports have observed a decrease in the $S / G$ ratio in waterlogged wood $(19,23)$, while others have reported no change in the ratio (24). A decrease in the S/G ratio can be caused by either selective removal of syringyl-rich cell walls or demethoxylation (i.e., formation of guaiacyl units) without any depolymerization of the lignin (20). The selective removal of a syringyl-rich component (e.g., by WRF) would also produce a corresponding increase in the Ac/Al ratio whereas demethoxylation alone would not affect the Ac/Al ratio (e.g., by bacteria or SRF).

THM-GC-MS studies of wood degradation over any timescale are scarce: a major work spanned from $8000 \mathrm{BP}$ to the sixth century, but did not consider the influence of differing environments: samples were taken from marine, freshwater and above-ground environments (20). In a 5 year study of fungal degradation of oak, intentional, controlled fungal degradation of oak showed $\mathrm{S} / \mathrm{G}$ decreased over 2 years, while Ac/Als and Ac/AlG increased over the same timescale (25). Pyrolysis-GC-MS studies have determined the stability of guaiacyl components of various oak species over centuries $(20,26)$.

Our long-range study of English oak from marine environments allowed both the study of chemical changes in wet and waterlogged wood over 400 years and an assessment of the preservation of the wood chemistry of the Mary Rose after prolonged burial in a marine environment due to the application of a consolidant for conservation purposes. After her keel was laid in 1510, the Mary Rose sailed for over 30 years before sinking to the bottom of the Solent in 1545. Preserved under the seabed for over 400 years, she broke the surface in 1982 and was taken to Portsmouth Historic Dockyard for conservation. To compensate for the loss of wood 
components (typically cellulose and hemicellulose) the ship was sprayed with aqueous solutions of polyethylene glycol (PEG) following methods used on other similar projects (e.g., Vasa (27)). Two PEG solutions with differing chain lengths of PEG were used, PEG 200 followed by PEG 2000. Following consolidation, the ship has been drying in environmentally controlled conditions since $2013(28,29)$.

The Mary Rose sample was taken using an incremental borer. This sample presented a transect across the wooden beam which formed the exterior layer of the hull. Because relatively large and well-structured volumes of sample were available for study, THM-GC-MS measurements were made using subsamples taken along the sample from the outer, exterior, "edge" and the inside "core," as an indicator of the effects of differing exposures to seawater. An additional untreated and dry sample of the Mary Rose was studied in order to gauge the effect of the PEG on preserving the wood chemistry due to burial. A representative GC-MS chromatogram is presented in Figure 1. Guiacyl and syringyl were identified in all the samples (Table 2). Peak areas were used to calculate the S/G, Ac/Als, and Ac/AlG ratios(25).

After a distinguished 122-year naval history, including the Battle of Trafalgar (1805), Her Majesty's Ship (HMS) Victory was permanently dry-docked in 1992. Whilst in dry dock, her bilges were allowed to dry out. The sample from HMS Victory was from original frame material which had been removed due to deathwatch beetle activity; it had been treated with the pest control agent benzalkonium chloride prior to removal. No other information about collection methods was available.

HMS Unicorn, built in 1824, is one of the oldest continuously afloat ships in the world. Built to replace ships lost in the Napoleonic Wars at the end of the age of sail, her service history involved no major battles, and hence the historic fabric of her hull is largely intact. Samples were collected directly from the wet bilges with the aid of a hammer and chisel. The hold has previously been treated for fungal activity (30), although the agent used is unknown.

SB Tollesbury was constructed in 1901, not for naval purposes, but for transporting cargo around the Thames estuary in southeast England; her bilges have been continuously wet for 118 years (31). The sample was collected manually from a frame in the wet bilges during a routine dry docking.

\section{Results and Discussion}

One of the core aliquots (out of multiple taken for triplicate analysis as detailed in the Methods section) from the treated Mary Rose sample was noticeably different from the others (and subsequently excluded from $S / G$ and acid-aldehyde calculations). This sample contains several compounds that appear to be from pitch pine, which is common in marine artifacts (32). The most abundant compounds in the thermochemolysis chromatogram are dehydroabietane and methylpimaran-18-oate. Other diterpenoid compounds identified include tetrahydroretene, simonellite, retene and dehydroabietic acid. Other compounds associated with the above diterpenoids include cadalene and 1,7-dimethylphenanthrene (for structures see (33)). Pitch pine has previously been positively identified from Mary Rose artefacts $(32,34)$, and the distribution of compounds present in the sample described here is also consistent with them being from pitch pine.

The Ac/Als and Ac/Alg ratios vary between samples (Figure 2). The values for SB Tollesbury, and HMS Victory are elevated compared to the value for modern oak, while there are large errors on 
HMS Unicorn samples. These four samples have a general upwards tendency with increasing vessel age.

Of the Mary Rose samples, the core sample falls below the modern oak sample for both Ac/Als and Ac/AlG. The edge sample shows high variation, with the guiacyl Ac/Al ratio substantially higher than all the other samples, especially modern oak. This is consistent with the pattern established by the other four samples. The Mary Rose edge syringyl ratio is indistinguishable from both modern oak and the untreated Mary Rose sample..

The S/G ratios of the modern oak, HMS Unicorn and HMS Victory samples are indistinguishable (Figure 3), with the value for SB Tollesbury remaining above 1.5. Two of the younger vessels (HMS Unicorn, and HMS Victory) have $S / G$ ratios indistinguishable from the $S / G$ ratio of modern oak (Figure 3). These four samples establish a typical $S / G$ around 2 and above 1.5 for historic waterlogged wood.

The Mary Rose samples have a broader range of values. The untreated and edge samples from the Mary Rose are between 1.5 and 2, while the core Mary Rose sample has by far the lowest S/G ratio, well below that of modern oak or any of the other samples.

Overall (excluding the core Mary Rose sample), the S/G ratio in English Oak does not change substantially with time under marine conditions. This is opposite to that expected by comparison with bacterial degradation, where this ratio is expected to decline (25). These $\mathrm{S} / \mathrm{G}$ abundances also differ from a long-range study of archaeological oak in dry and wet environments using pyrolysisGC-MS, which suggested that $S$ should decline early in the degradation process (20). This difference can be explained by our focus on samples from marine environments, where $S$ is not expected to decline.

By considering the Ac/Al and S/G ratios together (Figure 4), the effects of different environments on English Oak can be summarized. This sample set contains a source sample (modern oak); samples from working vessels in marine environments (SB Tollesbury and HMS Unicorn); and samples from conserved vessels in dry dock (HMS Victory, Mary Rose). Their paths to dry dock differed: HMS Victory went directly from being a working vessel to conservation in dry dock, while Mary Rose spent centuries under the seabed before being conserved in dry dock. Considering Figure 4, the Mary Rose core sample stands out as having both a low S/G ratio and low Ac/Al ratios. This indicates that this sample has potentially experienced different processes.

Within the Mary Rose samples, several different environments are represented. The differences between the untreated Mary Rose sample that received no conservation, and the samples that were treated with PEG can be used to understand the ability of PEG to chemically and physically preserve the wood. The sample without PEG has undergone chemical and physical degradation during the 30 years following retrieval from the sea floor, and hence has different properties. PEG treatment is also dependent on the distance from the surface of the artifact: PEG 200 will go about $4-5 \mathrm{~cm}$ into the wood, PEG 2000 goes about $1-2 \mathrm{~cm}$. The edge subsample will have received more PEG2000, whereas the core sample will have received only PEG 200 if any (35). These effects have been confirmed using various diagnostic techniques (36). Within the treated sample, the edge subsample from the outside of the hull would have been exposed to seawater and burial after sinking, while the core subsample deeper within the beam was less directly exposed to the effects of continuously refreshed deep seawater. Thus, the Mary Rose sample set represents three environments: material which has been exposed to the atmosphere for 30 years with no protection and material which has been preserved with PEG, which can be subdivided into material which 
was exposed to seawater over 400 years (the edge) and material which has been more protected by its position in the interior of the beam (the core).

All samples studied which have not been treated with $P E G$ have $S / G$ ratios similar to that of modern oak fresh from the tree (Figure 3). In the case of the Mary Rose, the S/G ratios vary greatly depending whether they were treated and the location of the subsample used for THM-GC-MS analysis. Lack of PEG treatment could mean that the surface of the sample has continuously degraded since being recovered from the sea floor in 1982 and chemical degradation due to atmospheric exposure has led to physical degradation and ultimately disintegration and complete loss, therefore the material available for chemical analysis is the underlying, "fresh," oak which has experienced a different level of chemical degradation (Figure 5). The S/G ratio and the Ac/AI ratios for this sample are close to those of modern oak, unlike those of the treated Mary Rose samples, suggesting that PEG treatment could have preserved the chemical degradation of the lignin at the time of treatment, consistent with a similar study of the Hanson Logboat, a 3000 year old specimen of English Oak preserved in peat (37). This study also reported decreased S/G ratios, less dramatic than that observed here, which may be attributed to the different burial environments. These ratios are also consistent with those determined by HMDS-pyrolysis-GCMS on fresh-waterlogged oak samples from $9^{\text {th }}-12^{\text {th }}$ century Poland(38).

In the case of the edge and core Mary Rose samples, the PEG treatment appears to have preserved the oxidative degradation state of the wood as it was before the ship was raised from the seafloor, as there are clear differences to the untreated sample and between the treated core and edge sample. The edge sample has an $S / G$ ratio higher than the core sample, but lower than that of modern oak, consistent with the century-old wood of SB Tollesbury, indicating that some loss of syringyl compounds has occurred. The low S/G ratio of the core of the Mary Rose sample is in alignment with 437 years of burial (23). It is well documented by a number of techniques, including pyrolysis-GC-MS, that syringyl components degrade more quickly than their corresponding guiaiacyl counterparts during burial. Intriguingly, the Ac/Al ratios for the core and edge samples are respectively lower and higher than those of modern oak, suggesting that different processes dominated in different locations within the wooden beam of the hull.

When the Ac/Al ratios are considered, degradation by biological activity becomes an additional factor to be considered. The edge of the Mary Rose, with low S/G and high Ac/Al ratios, is potentially consistent with fungal degradation. Meanwhile, the Mary Rose core sample shows a very low S/G ratio coupled with low Ac/Al ratios, which suggests bacterial degradation has occurred. The Mary Rose wood is known to be associated with bacterial communities (39). Studies using different analytical techniques (py-GCMS, py(HMDS)-GCMS, classical wet chemistry analysis) suggest that $S / G$ ratios may also be lower in heartwood samples compared to sapwood samples due to fundamental differences in the cell structure of the living tree as it ages $(38,40)$. These three factors: burial, low initial values, and bacterial degradation, may have combined to produce the uniquely low $\mathrm{S} / \mathrm{G}$ and $\mathrm{Ac} / \mathrm{Al}$ ratios in the Mary Rose core sample.

In Figure 4, the Mary Rose core sample stands alone as very chemically degraded but unoxidized (compared to modern oak). All other samples show less chemical degradation paired with greater oxidation relative to modern oak. This suggests that the core Mary Rose sample has been protected from oxidative effects by its location within the beam, while chemical effects from bacterial degradation occurred, possibly to different degrees, in both locations. Further, as it is likely heartwood, it may well have started with a lower S/G ratio. The combination of these factors resulted in the very low value observed here. Within the other samples, considering only the guiacyl acid-to-aldehyde ratio, there is a further division: Mary Rose No PEG, Modern Oak and HMS Unicorn plot together, while HMS Victory, SB Tollesbury and Mary Rose Edge form a separate group. Except for SB Tollesbury, the members of this group are the samples which have benefited from conservation after centuries of wear. SB Tollesbury may simply be too young (i.e., without 
conservation) and as her hull ages, this value may shift towards that of the vessels which have not received treatment. This pattern is also somewhat preserved in the syringyl acid-to-aldehyde data.

\section{Conclusions}

A suite of samples of English oak stored in marine environments for durations of up to 4 centuries was studied using THM-GC-MS. As a result of these measurements, we offer an interpretation of the successful use of PEG to conserve the chemical state of the Mary Rose wood after burial. Additionally, the use of PEG has preserved the core sample in a state of chemical degradation which is not observed in the other maritime oak samples, which we attribute to bacterial activity. Our data also establishes a baseline for assessing whether a ship has been biologically degraded. However, the majority of the samples are very similar to recently collected oak, suggesting that complete immersion of English Oak in seawater reduces chemical degradation.

\section{Materials and Methods}

Sample collection: Samples were physically removed from the vessels using brute force. Sample location varied but were preferentially taken from wet bilges or frames of working vessels (to ensure maximum time spent submerged). Subsequent aliquots for analysis were shaved from the main sample with a clean surgical blade.

TMAH-assisted thermochemolysis-gas chromatography-mass spectrometry (GC-MS): A small aliquot $(<50 \mathrm{ug})$ of the wood was loaded into a quartz pyrolysis tube, which was plugged with loosely packed quartz wool at both ends. Each sample was injected with $50 \mathrm{ul}$ of tetramethylammonium hydroxide (TMAH) in methanol (25:75). The samples were allowed to evaporate for $12 \mathrm{~h}$. Subsequently, samples were heated in a CDS Pyroprobe 1500 at the thermochemolysis temperature of $350^{\circ} \mathrm{C}$ and an interface temperature of $320^{\circ} \mathrm{C}$. The thermochemolysis products were then fed directly (splitless) onto an Agilent Technology 6890 gas chromatograph joined to a 5973 mass spectrometer. Separation was performed on a $30 \mathrm{~m}$ J\&W Scientific DB-5MS Ultra Inert column. Helium flow was set at $1.1 \mathrm{ml} \mathrm{min}^{-1}$. The GC oven was initially held at $40^{\circ} \mathrm{C}$ for $2 \mathrm{~min}$, then the temperature ramped at $5^{\circ} \mathrm{C} \mathrm{min}^{-1}$ to $310^{\circ} \mathrm{C}$, where it was held for $10 \mathrm{~min}$, for a total run length of $66 \mathrm{~min}$. All samples were run in triplicate. Identification of products was based on (41).

Separation of conservation agents, including polyethylene glycol (PEG), from the wood of the original artifact, has been performed by double-shot hexamethyldisilane (HMDS)-pyrolysis-GCMS(42). One advantage of THM-GC-MS is insensitivity to PEG treatment, as PEG is not broken down by tetramethylammonium hydroxide (TMAH) and thus is not present in the resulting gas chromatograms.

Experimental blanks were run before every sample measurement to ensure the GC column and pyrolysis unit were free of contaminants. Samples of PEG were run to confirm that TMAH has little effect on PEG present in the Mary Rose samples.

Analysis: S/G ratios were calculated using the S4-8 and G4-8 peak areas. The ratios (Ad/Al)s,G were calculated using the peak areas of S6 and S4, G6 and G4 respectively. Table 1 gives the structures, chemical names, and characteristic ions of the compounds used. At least four different aliquots of each sample or subsample were taken to provide an average and standard deviation for each value.

Data availability: A complete dataset can be downloaded from https://doi.org/10.5281/zenodo.4742499. 
Author Contributions: W.M. and E J.S. collected samples; W. M., J.S.W. and M.A.S. designed research; W.M. performed research; W.M., J.S.W and M.A.S. analyzed data. All authors wrote paper.

Competing Interest Statement: The authors declare no conflict of interest.

Keywords: waterlogged archaeological wood, Mary Rose, English Oak, lignin, conservation; THM-GC-MS.

\section{Acknowledgments}

Diana McCormack on HMS Victory and SB Tollesbury for supplying sample, and HMS Unicorn for facilitating sampling. We are grateful to S. H. Royle and E. H.-W. for helpful comments during revision.

\section{References}

1. E. V. Wright, R. E. M. Hedges, A. Bayliss, R. V. de Noort, New AMS radiocarbon dates for the North Ferriby boats-a contribution to dating prehistoric seafaring in northwestern Europe. Antiquity 75, 726-734 (2001).

2. R. Larn, B. Larn, Shipwreck Index of the British Isles, Vol. 1: Isles of Scilly, Cornwall, Devon, Dorset, 1st Edition edition (Tor Mark Press, 1995).

3. Ships and Boats: Prehistory to Present Selection Guide (2017).

4. K. E. High, K. E. H. Penkman, A review of analytical methods for assessing preservation in waterlogged archaeological wood and their application in practice. Herit. Sci. 8, 83 (2020).

5. S. Steelandt, A.-C. Pierson-Wickmann, N. Bhiry, D. Marguerie, M. B.-L. Coz, Chemical Differentiation between Immersed and Dry Wood Samples in Nunavik (Northern Quebec, Canada): Preliminary Results. Arct. Antarct. Alp. Res. 48, 315-325 (2016).

6. J. J. Łucejko, F. Modugno, M. P. Colombini, M. Zborowska, Archaeological wood from the Wieliczka Salt Mine Museum, Poland - Chemical analysis of wood degradation by Py(HMDS)-GC/MS. J. Cult. Herit. 13, S50-S56 (2012).

7. N. Macchioni, B. Pizzo, C. Capretti, An investigation into preservation of wood from Venice foundations. Constr. Build. Mater. 111, 652-661 (2016).

8. J. Evelyn, A. (Alexander) Hunter, Silva: or, A discourse of forest-trees, and the propagation of timber in His Majesty's dominions, as it was delivered in The Royal society, on the 15th of October 1662 .. (York, Wilson, 1801) (November 7, 2018).

9. N. B. Pedersen, N. Gierlinger, L. G. Thygesen, Bacterial and abiotic decay in waterlogged archaeological Picea abies (L.) Karst studied by confocal Raman imaging and ATR-FTIR spectroscopy. Holzforschung 69, 103-112 (2015).

10. J. J. Lucejko, et al., Oak wood degradation processes induced by the burial environment in the archaeological site of Biskupin (Poland). Herit. Sci. 8, 44 (2020). 
11. J. M. Challinor, Review: the development and applications of thermally assisted hydrolysis and methylation reactions. J. Anal. Appl. Pyrolysis 61, 3-34 (2001).

12. J. M. Challinor, Characterisation of wood by pyrolysis derivatisation-gas chromatography/mass spectrometry. J. Anal. Appl. Pyrolysis 35, 93-107 (1995).

13. F. Shadkami, R. Helleur, Recent applications in analytical thermochemolysis. J. Anal. Appl. Pyrolysis 89, 2-16 (2010).

14. J. M. Palmer, C. S. Evans, B. S. Hartley, T. Atkinson, M. D. Lilly, The enzymic degradation of lignin by white-rot fungi. Philos. Trans. R. Soc. Lond. B Biol. Sci. 300, 293-303 (1983).

15. C. H. Vane, The molecular composition of lignin in spruce decayed by white-rot fungi (Phanerochaete chrysosporium and Trametes versicolor) using pyrolysis-GC-MS and thermochemolysis with tetramethylammonium hydroxide. Int. Biodeterior. Biodegrad. 51, $67-75$ (2003).

16. M. Bardet, et al., 13C high-resolution solid-state NMR for structural elucidation of archaeological woods. Prog. Nucl. Magn. Reson. Spectrosc. 55, 199-214 (2009).

17. P. G. Hatcher, I. A. Breger, W. L. Earl, Nuclear magnetic resonance studies of ancient buried wood-I. Observations on the origin of coal to the brown coal stage. Org. Geochem. 3, 49-55 (1981).

18. M. A. Wilson, I. M. Godfrey, J. V. Hanna, R. A. Quezada, K. S. Finnie, The degradation of wood in old Indian Ocean shipwrecks. Org. Geochem. 20, 599-610 (1993).

19. C. Saiz-Jimenez, J. J. Boon, J. I. Hedges, J. K. C. Hessels, J. W. De Leeuw, Chemical characterization of recent and buried woods by analytical pyrolysis: Comparison of pyrolysis data with 13C NMR and wet chemical data. J. Anal. Appl. Pyrolysis 11, 437-450 (1987).

20. P. F. van Bergen, I. Poole, T. M. A. Ogilvie, C. Caple, R. P. Evershed, Evidence for demethylation of syringyl moieties in archaeological wood using pyrolysis-gas chromatography/mass spectrometry. Rapid Commun. Mass Spectrom. 14, 71-79 (2000).

21. F. Modugno, E. Ribechini, M. Calderisi, G. Giachi, M. P. Colombini, Analysis of lignin from archaeological waterlogged wood by direct exposure mass spectrometry (DE-MS) and PCA evaluation of mass spectral data. Microchem. J. 88, 186-193 (2008).

22. A. Agarwal, M. Rana, J.-H. Park, Advancement in technologies for the depolymerization of lignin. Fuel Process. Technol. 181, 115-132 (2018).

23. J. I. Hedges, G. L. Cowie, J. R. Ertel, R. James Barbour, P. G. Hatcher, Degradation of carbohydrates and lignins in buried woods. Geochim. Cosmochim. Acta 49, 701-711 (1985).

24. J. J. Łucejko, F. Modugno, E. Ribechini, J. C. del Río, Characterisation of archaeological waterlogged wood by pyrolytic and mass spectrometric techniques. Anal. Chim. Acta 654, 26-34 (2009). 
25. C. H. Vane, T. C. Drage, C. E. Snape, Biodegradation of Oak ( Quercus alba) Wood during Growth of the Shiitake Mushroom ( Lentinula edodes ): A Molecular Approach. J. Agric. Food Chem. 51, 947-956 (2003).

26. M. Traoré, J. Kaal, A. Martínez Cortizas, Potential of pyrolysis-GC-MS molecular fingerprint as a proxy of Modern Age Iberian shipwreck wood preservation. J. Anal. Appl. Pyrolysis 126, 1-13 (2017).

27. B. Håfors, Conservation of the Swedish warship Vasa from 1628 (Vasamuseet, 2001).

28. G. McConnachie, "Air drying behaviour of waterlogged archaeological woods from the Tudor warship Mary Rose.," Portsmouth University, United Kingdom. (2005).

29. E. J. Schofield, G. McConnachie, M. Jones, Air drying of the Mary Rose hull in Proceedings of the 12th ICOM-CC WOAM Conference, (2013), p. 398.

30. N. A. White, J. W. Palfreyman, H. J. Staines, Fungal colonization of the keelson timbers of a nineteenth century wooden frigate. Mater. Org. 30, 117-131 (1996).

31. M. Simmons, Sandwich Local History Society, Society for Sailing Barge Research (Great Britain), Felton's Sandwich sailing barges (Chaffcutter Books on behalf of the Sandwich Local History Society, 2012).

32. N. Robinson, R. P. Evershed, W. J. Higgs, K. Jerman, G. Eglinton, Proof of a pine wood origin for pitch from Tudor (Mary Rose) and Etruscan shipwrecks: application of analytical organic chemistry in archaeology. Analyst 112, 637-644 (1987).

33. A. Otto, B. R. T. Simoneit, Chemosystematics and diagenesis of terpenoids in fossil conifer species and sediment from the Eocene Zeitz formation, Saxony, Germany. Geochim. Cosmochim. Acta 65, 3505-3527 (2001).

34. R. P. Evershed, K. Jerman, G. Eglinton, Pine wood origin for pitch from the Mary Rose. Nature 314, 528-530 (1985).

35. Z. Walsh, E.-R. Janeček, M. Jones, O. A. Scherman, Natural polymers as alternative consolidants for the preservation of waterlogged archaeological wood. Stud. Conserv. 62 , 173-183 (2017).

36. E. R. Aluri, et al., The Formation of Chemical Degraders during the Conservation of a Wooden Tudor Shipwreck. ChemPlusChem 85, 1632-1638 (2020).

37. A. P. Pinder, I. Panter, G. D. Abbott, B. J. Keely, Deterioration of the Hanson Logboat: chemical and imaging assessment with removal of polyethylene glycol conserving agent. Sci. Rep. 7, 13697 (2017).

38. J. J. Łucejko, M. Zborowska, F. Modugno, M. P. Colombini, W. Prądzyński, Analytical pyrolysis vs. classical wet chemical analysis to assess the decay of archaeological waterlogged wood. Anal. Chim. Acta 745, 70-77 (2012).

39. J. Preston, J. E. M. Watts, M. Jones, Novel Bacterial Community Associated with 500Year-Old Unpreserved Archaeological Wood from King Henry VIIl's Tudor Warship the Mary Rose. Appl. Environ. Microbiol. 78, 8822-8828 (2012). 
40. J. J. Łucejko, et al., Deterioration effects of wet environments and brown rot fungus Coniophora puteana on pine wood in the archaeological site of Biskupin (Poland). Microchem. J. 138, 132-146 (2018).

41. T. R. Filley, K. G. J. Nierop, Y. Wang, The contribution of polyhydroxyl aromatic compounds to tetramethylammonium hydroxide lignin-based proxies. Org. Geochem. 37, 711-727 (2006).

42. D. Tamburini, J. J. fucejko, E. Ribechini, M. P. Colombini, New markers of natural and anthropogenic chemical alteration of archaeological lignin revealed by in situ pyrolysis/silylation-gas chromatography-mass spectrometry. J. Anal. Appl. Pyrolysis 118, 249-258 (2016). 
Figures and Tables

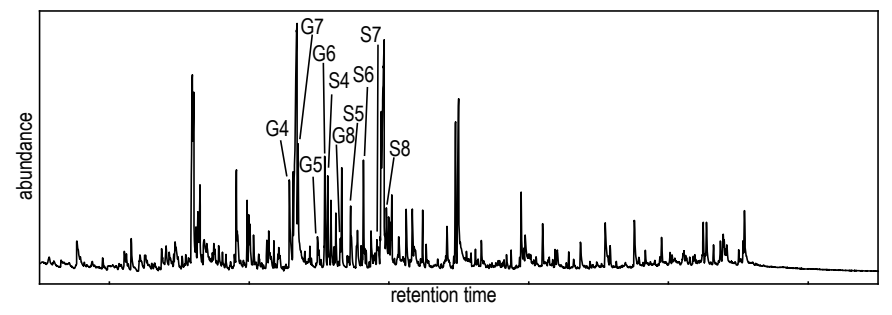

Figure 1. Representative THM-GCMS chromatogram of sample from the Mary Rose Compounds are listed in Table 1. 


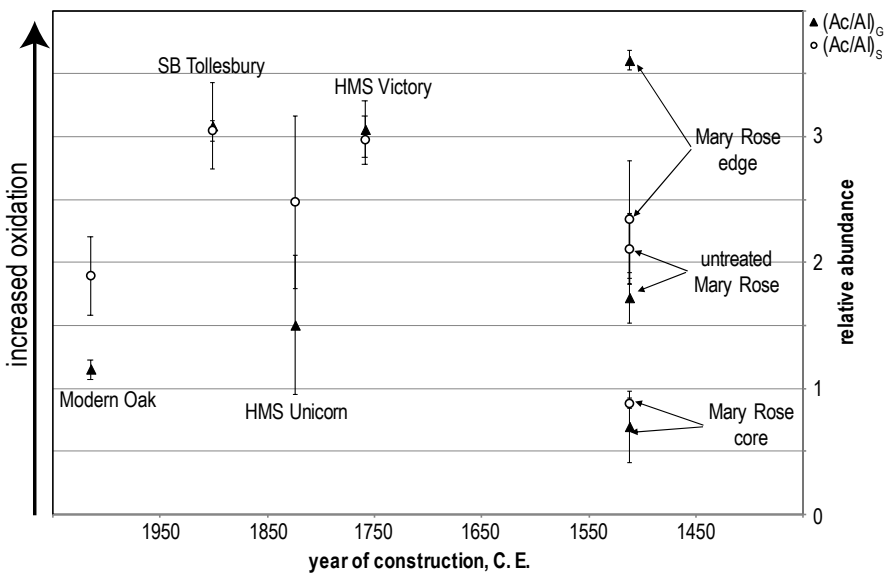

Figure 2. Acid-Aldehyde Ratios of Historical Vessels. Triangles are Ac/Alg values, and open circles are Ac/Als values. 


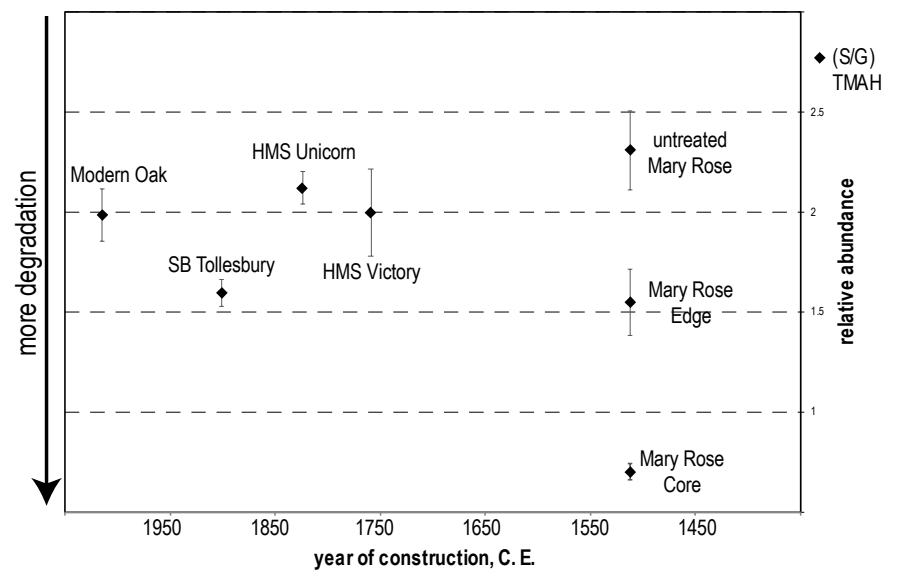

Figure 3. S/G Ratios of Historic British Vessels. Error bars calculated over a minimum of 4 samples. 


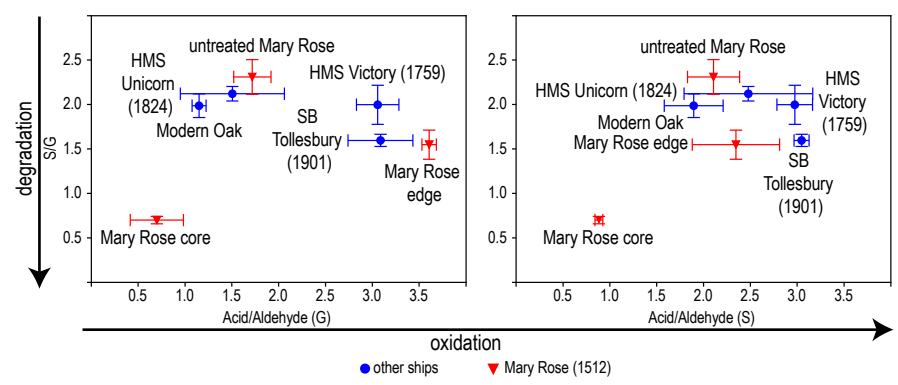

Figure 4. Oxidation vs. degradation in historic vessels and shipwrecks, syringyl and guiacyl fractions. Red circles are data from the Mary Rose; blue circles are data from HMS Unicorn, HMS Victory, SB Tollesbury, and a modern oak sample. 


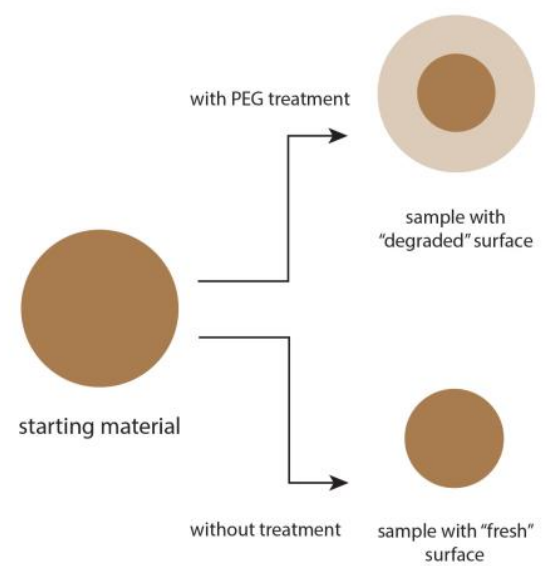

Figure 5. Schematic illustration of degradation scenarios in Mary Rose samples. 
Table 1. English Oak samples

\begin{tabular}{|l|l|l|l|}
\hline Ship & $\begin{array}{l}\text { Keel } \\
\text { laid/launched }\end{array}$ & $\begin{array}{l}\text { Sample } \\
\text { location }\end{array}$ & Additional Comments \\
\hline Mary Rose & 1512 & Keel at stern end & $\begin{array}{l}\text { Sample taken through wooden } \\
\text { beam; additional sample without } \\
\text { PEG Treatment from stores }\end{array}$ \\
\hline HMS Victory & 1752 & Bow frame hold & $\begin{array}{l}\text { Removed due to deathwatch beetle } \\
\text { activity }\end{array}$ \\
\hline HMS Unicorn & 1824 & $\begin{array}{l}\text { wet bilges, } \\
\text { starboard of } \\
\text { keelson } \\
\text { (amidships) }\end{array}$ & $\begin{array}{l}\text { In line with \#6 post; collected from } \\
\text { in situ for this study }\end{array}$ \\
\hline SB Tollesbury & 1901 & $\begin{array}{l}\text { wet bilge floor } \\
\text { frame (2nd aft of } \\
\text { mast stem) }\end{array}$ & collected during routine dry docking \\
\hline Modern Oak & -- & -- & $\begin{array}{l}\text { deadfall branch collected from } \\
\text { English Oak in Lincoln's Inn Fields, } \\
\text { (51 } 31^{\circ} \text { '00.2"N 006'55.7"W) }\end{array}$ \\
\hline
\end{tabular}


Table 2. Derivatization products of lignin: (Hatcher 1995, Vane 2000)

\begin{tabular}{|c|c|c|c|}
\hline Compound & Chemical name & Characteristic ion & Structure \\
\hline G4 & $\begin{array}{l}\text { 3,4-dimethoxybenzaldehyde } \\
\text { (vanillin) }\end{array}$ & $95,52,77$ & \\
\hline G5 & 3,4-dimethoxyacetophenone & $165,79,137$ & \\
\hline G6 & $\begin{array}{l}\text { 3,4-dimethoxybenzoic acid, } \\
\text { methyl ester }\end{array}$ & $165,79,137$ & \\
\hline G7 & $\begin{array}{l}\text { cis-1-(3,4-dimethoxyphenyl)- } \\
\text { 2-methoxyethylene }\end{array}$ & $179,151,91$ & \\
\hline G8 & $\begin{array}{l}\text { trans-1-(3,4- } \\
\text { dimethoxyphenyl)-2- } \\
\text { methoxyethylene }\end{array}$ & $179,151,91$ & \\
\hline S4 & $\begin{array}{l}3,4,5- \\
\text { trimethoxybenzaldehyde }\end{array}$ & 125,181110 & \\
\hline S5 & $\begin{array}{l}3,4,5- \\
\text { trimethoxyacetophenone }\end{array}$ & $195,74,87$ & \\
\hline S6 & 3,4,5-trimethoxybenzoate & $211,155,195$ & \\
\hline S7 & $\begin{array}{l}\text { cis-1-(3,4,5- } \\
\text { trimethoxyphenyl)-2- } \\
\text { methoxyethylene }\end{array}$ & $209,181,151$ & \\
\hline S8 & $\begin{array}{l}\text { trans-1-(3,4,5- } \\
\text { trimethoxyphenyl)-2- } \\
\text { methoxyethylene }\end{array}$ & $209,181,151$ & \\
\hline
\end{tabular}


